\title{
EFFECT OF TOOL ECCENTRICITY ON MICROSTRUCTURE AND PROPERTIES OF FSW JOINTS MADE OF AL 7075 T6 ALLOY
}

\author{
Rafał Burek ${ }^{1}$, Dawid Wydrzyński', Jacek Andres ${ }^{1}$, Agata Wrońska' \\ 1 PZL Mielec, a Sikorsky Company, ul. Wojska Polskiego 3, 39-300 Mielec, Poland, e-mails: rafal.burek@lmco. \\ com, dwydrzynski@prz.edu.pl, jacek.andres@Imco.com, agata.wronska@Imco.com
}

Received: 2017.10.28

Accepted: 2017.11.13

Published: 2017.12 .05

\begin{abstract}
The aim of this paper was to present preliminary results of researches conducted in PZL Mielec within the FAST FSW project (INNOLOT program) on the influence of tool eccentricity on microstructure and mechanical properties of $1.6 \mathrm{~mm}$ and $0.8 \mathrm{~mm}$ thick A1 7075 T6 sheets joints. Samples were performed using CNC milling machine. The range of tool eccentricity was $0-0.3 \mathrm{~mm}$, rotational speed and feed rate were variable. The influence of the applied welding parameters on microstructure and mechanical properties of joints was assessed on the basis of metallographic inspections and tensile tests. Microstructural observations have shown that the change of FSW tool eccentricity affects the weld geometry: the mixing zone depth, the weld width, or the shape of the contact line.
\end{abstract}

Keywords: FSW, Al 7075, joining.

\section{INTRODUCTION}

Friction Stir Welding (FSW) is one of the newest methods of joining materials. The invention of this method (TWI, Cambridge, 1991) made it possible to combine materials recognized so far as not recommended for welding, e. g. aluminum alloys $2 \mathrm{xxx}$ and $7 \mathrm{xxx}$ [2]. The main advantage of this process is possibility of joining solid state materials, what eliminates the risk of typical welding defects (e. g. gas inclusions, hot cracks, shrinkage) occurring in a weld $[1,9]$. The FSW process is very complex and the quality of the weld depends on many factors as linear velocity of welding, rotational speed, tool plunge depth, clamping force or torque. Mechanism of material transport in a weld is affected by a tool: its geometry, angle of inclination and eccentricity. The impact of FSW process parameters has been broadly characterized among other papers $[1,6]$. Tool eccentricity was not broadly discussed in scientific elaborations, so there is a lack of unequivocal information about influence of eccen- tricity and its optimal values. The authors $[3,7,8$, 10] agree on the function of the tool eccentricity during the welding process: intensification of material mixing due to orbital motion of the tool's pin. It also has an influence, on the mechanism of transport of the plasticized material in the weld [5], and thus on the occurrence of volumetric defects in the weld, e.g. voids, contact line deformation and the creation of the hooking and cold lap.

This paper focuses on the influence of the eccentricity of the FSW tool on the microstructure and the mechanical properties of the $7075 \mathrm{~T} 6$ thinwalled sheet metal joints.

\section{RESEARCH TECHNIQUES}

The study used 7075 T6 aluminum alloy sheet, double-sided plated (AMS-QQ-A-250-13), thickness of sheets are shown in Figure 2. The main purpose of the experimental research was to determine the effect of eccentricity of tool pin and shoulder on the microstructure and 
properties of FSW joints. Tool eccentricity was achieved by making a hole in the pin holder so that the axis of the hole was offset by value of " $x$ " relative to the axis of the holder, as shown in Figure 1. Commercially available tool with screw line was used ( $\varnothing 4$ pin).

Reference joints were made using a tool without eccentricity and with use of tools with eccentricity values: $x=0.1 \mathrm{~mm} ; \mathrm{x}=0.2 \mathrm{~mm} ; \mathrm{x}=0.3 \mathrm{~mm}$. Specimens for strength test (AWS D17.3) and metallographic test were cut from $300 \mathrm{~mm}$ long joints. The sample and its dimensions are shown in Figure 2. The welding process was performed with the following parameters: rotational speed $\omega_{1}=700, \omega_{2}=1000, \omega_{3}=1300[\mathrm{rpm}]$ and feed rate $\mathrm{v} 1=100, \mathrm{v} 2=200, \mathrm{v} 3=300[\mathrm{~mm} / \mathrm{min}]$ maintaining a constant plunge depth. CNC milling machine SOLARUCE TA-20 AUTOMATIC was used to perform welding process. The joints were subjected to a visual inspection and then the samples for the destructive tests were cut.

Samples for metallographic tests were subjected to grinding, polishing and etching at ambi-

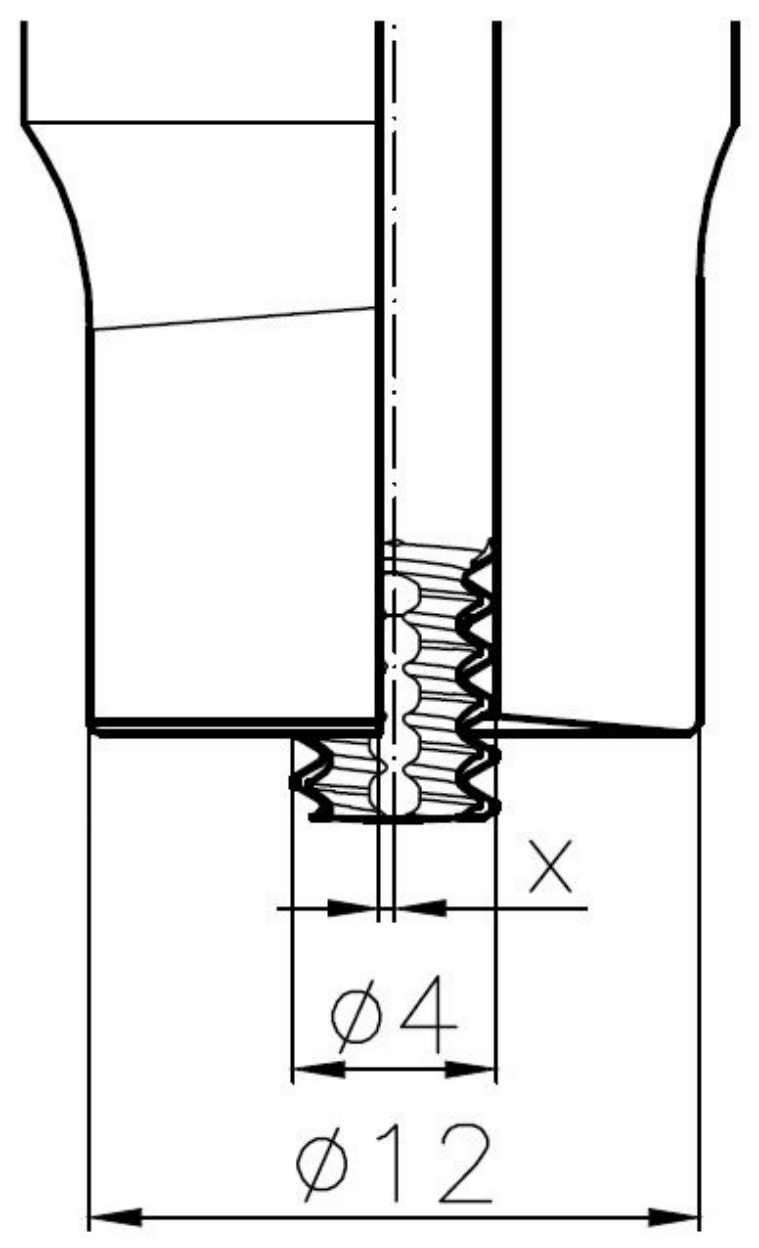

Fig. 1. Tool's dimensions ent temperature in a Keller's etch ( $5 \mathrm{ml} \mathrm{HF}, 15 \mathrm{ml}$ $\mathrm{HCl}, 25 \mathrm{ml} \mathrm{HNO}_{3}, 955 \mathrm{ml} \mathrm{H}_{2} \mathrm{O}$ ). Microstructural observations were done on microsections with use of digital optical microscope.

Tensile strength tests were performed on an MTS Landmark machine equipped with force and displacement sensors. For strength tests, four samples were assigned. Every time breaking force was registered. Broken samples were visually inspected. This allowed to precisely analyze the cause of joint breaking.

\section{TEST RESULTS AND DISCUSSION}

The primary function of eccentricity in the FSW tool is to intensify the mixing of the welded material. This is related to the amount of heat introduced to the welded material [5]. As the visual inspection of the joints showed, the face of the weld quality deteriorated with the increase of tool eccentricity. The flash was the smallest in the case of joints welded with use of eccentricity free tool $(\mathrm{x}=0 \mathrm{~mm})$, while the largest flash was found in joints welded with $0.3 \mathrm{~mm}$-eccentricity tool.

When a tool without eccentricity was used the surface of joint was smooth and only characteristic rings could be observed. Distance between rings increaased, with the increase of the feed rate. This distance reflects the number of revolutions of the tool per section of weld. In the case of joints made with eccentric tools $(x=0.2$ $\mathrm{mm}$ and $\mathrm{x}=0.3 \mathrm{~mm}$ ), there was a noticeable dust on the face of the weld - fine particles of welded material. Faces of welds of joints made with $0.1 \mathrm{~mm}$-eccentric tool were smooth or partially dusty. These small particles of welded material usually appear when the temperature of the weld is too high and material is plasticized more than it was required. On the other hand, in the analysed cases, a new portion of the non-plasticized material is constantly being delivered to the impact area of the tool as a result of its eccentricity. As a result, fine particles can be observed on the surface of the weld. In the case of the tested sheets, the appearance of surface unevenness is also related to the presence of the alclad on the surface of the welded metal.

The parameters of the welding process have a significant influence on the weld geometry: the width and depth of the mixing zone, the presence (or absence) of the voids and defects associated with the deformation of the contact line. In case of tested specimens sizes of mixing zone were con- 

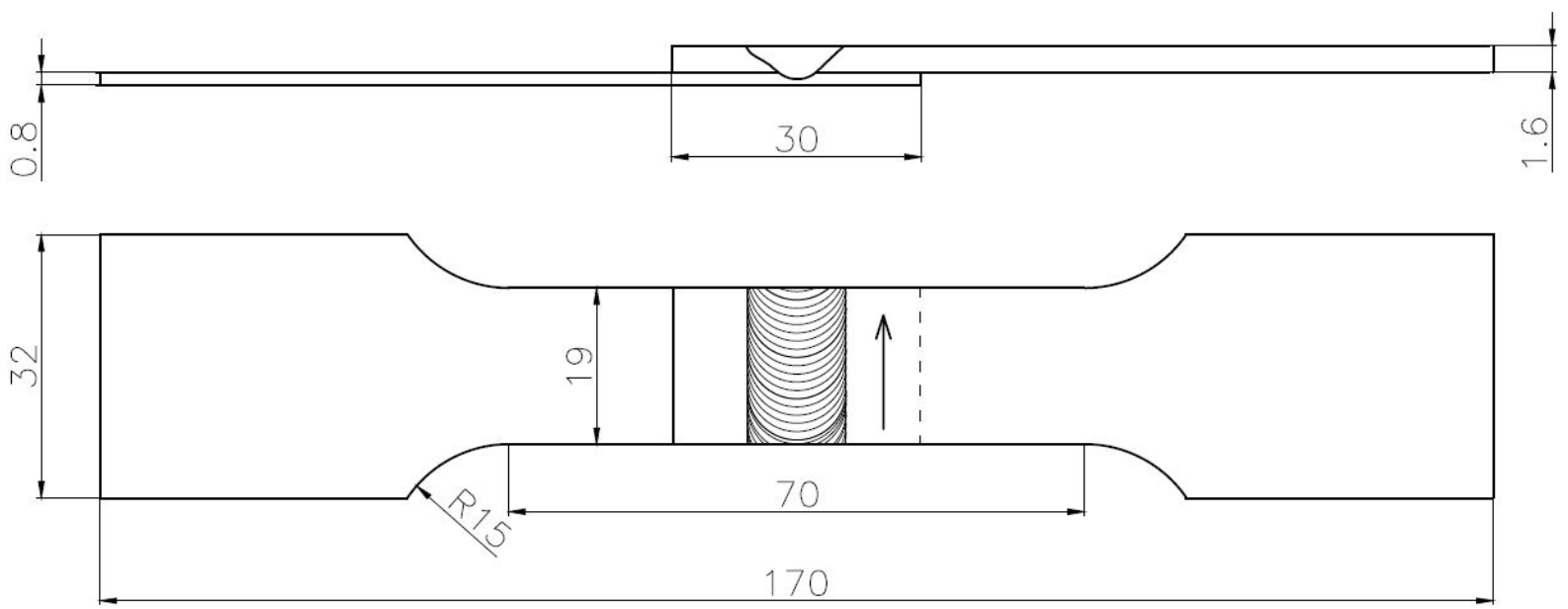

Fig. 2. Geometry of tensile test sample

Table 1. Weld faces of selected FSW joints

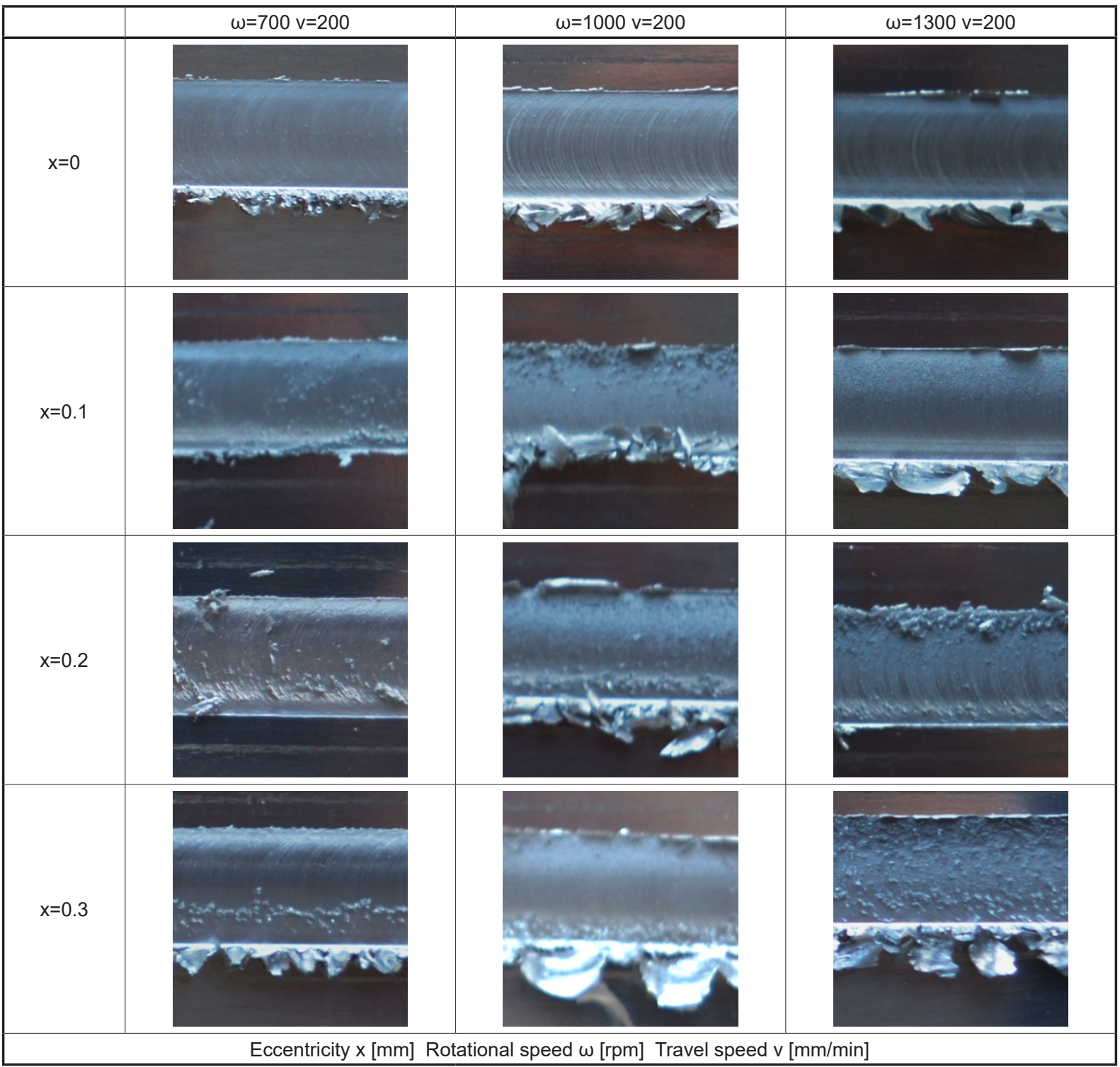


nected with rotational speed and feed rate (linear speed). Maintaining the same feed rate of welding (Table 2), the width and depth of the mixing zone are the greater, the higher the rotational speed is. This dependence is obvious and is the result of the amount of heat introduced into the welded material. Eccentricity lowers the temperature in the weld, as a portion of the non-plasticized material at a lower temperature is continuously fed into the area of tool impact. In addition, eccentricity impacts the mechanism of material transport in a weld. In the microstructure of the examined joints, distinct bands (so called onion rings) were placed concentric with each other in the case of tools without eccentricity or with eccentricity $\mathrm{x}=$ $0.1 \mathrm{~mm}$ (Table 2). Joints made with an eccentric tool $(\mathrm{x}=0.2 \mathrm{~mm}$ and $\mathrm{x}=0.3 \mathrm{~mm})$ also were characterized by strand microstructure. What is more, it was observed that the material movement was not only around the pin and below the surface of the shoulder. In zone of recrystallization, mainly on the side of advance and retraction welded material was also mixed up and down (Table 2). In addition, it was observed that welding using tools with eccentricity values of $x=0.2 \mathrm{~mm}$ and $\mathrm{x}=0.3$ $\mathrm{mm}$ resulted in large voids in these areas, except for high rotational speed welded joints, when the welding temperature was high enough to provide appropriate plasticization of the material (for all applied linear velocities). Welding with a tool with value of eccentricity $\mathrm{x}=0,1 \mathrm{~mm}$ limits the formation of voids. The best mixing of the welded material (the most homogeneous microstructure in the weld core and the absence of voids) was obtained using a tool without eccentricity - the temperature during the process was the highest. Microstructural observations showed that in the case of eccentricity free tool welding with high rotational speed leads to creation of hooking in the weld on advancing side (Figure 3). Defects associated with deformation of contact line do not appear in any joint produced using eccentric tool (Fig. 4).

Table 2. Microstructure of selected FSW joints

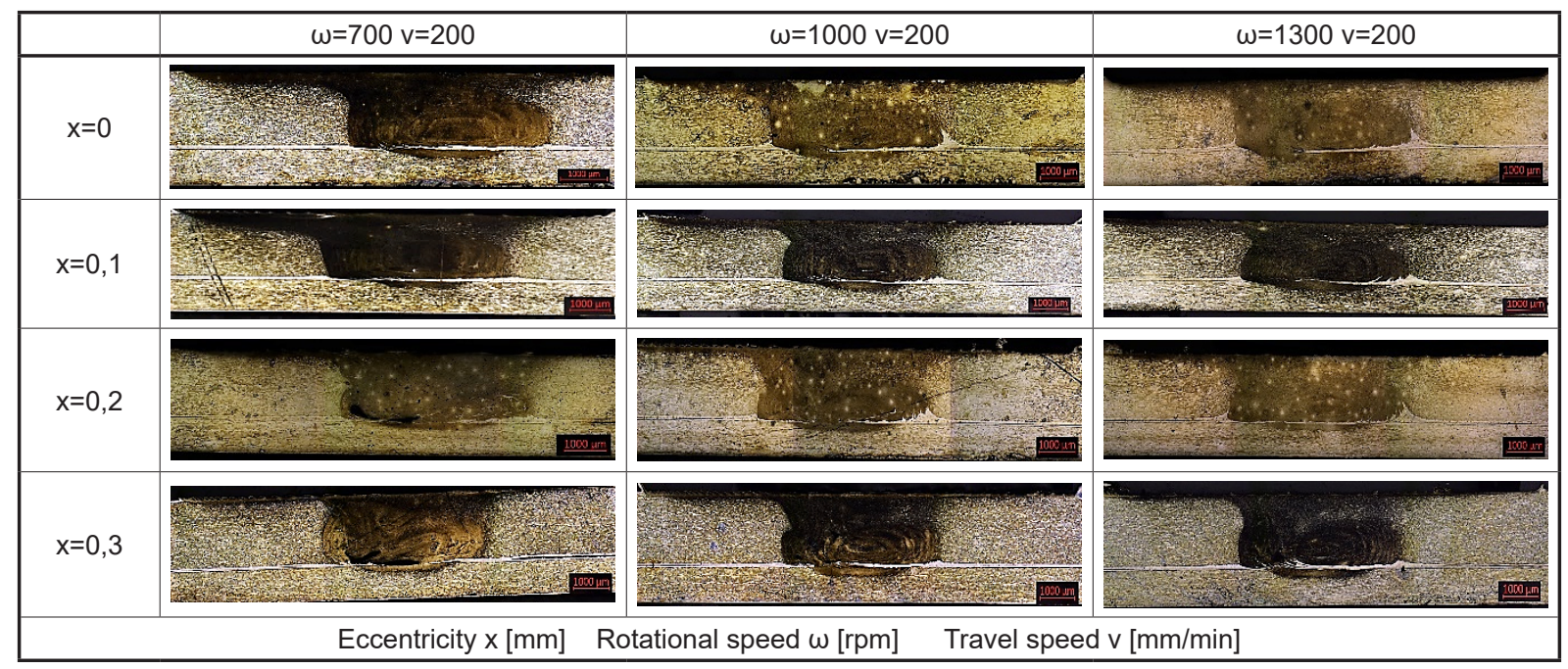

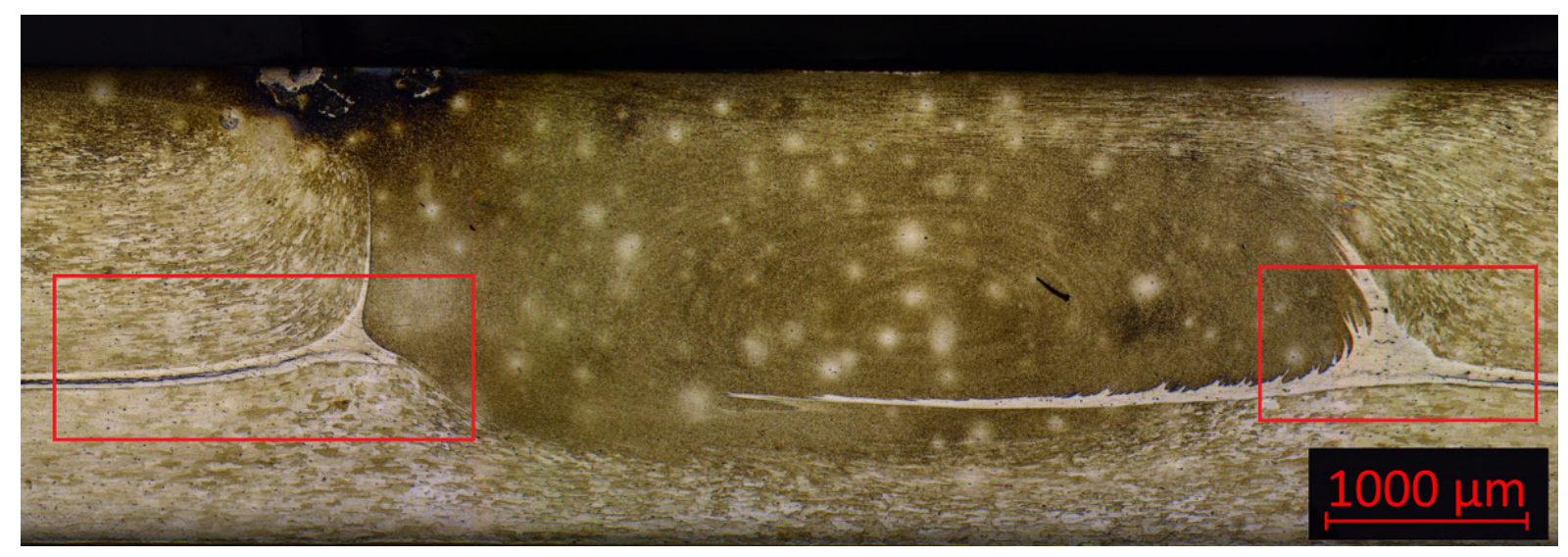

Fig. 3. Microstructure of joint welded with parameters: $\omega=1300 \mathrm{rpm} ; \mathrm{v}=100 \mathrm{~mm} / \mathrm{min} ; \mathrm{x}=0 \mathrm{~mm}$ 


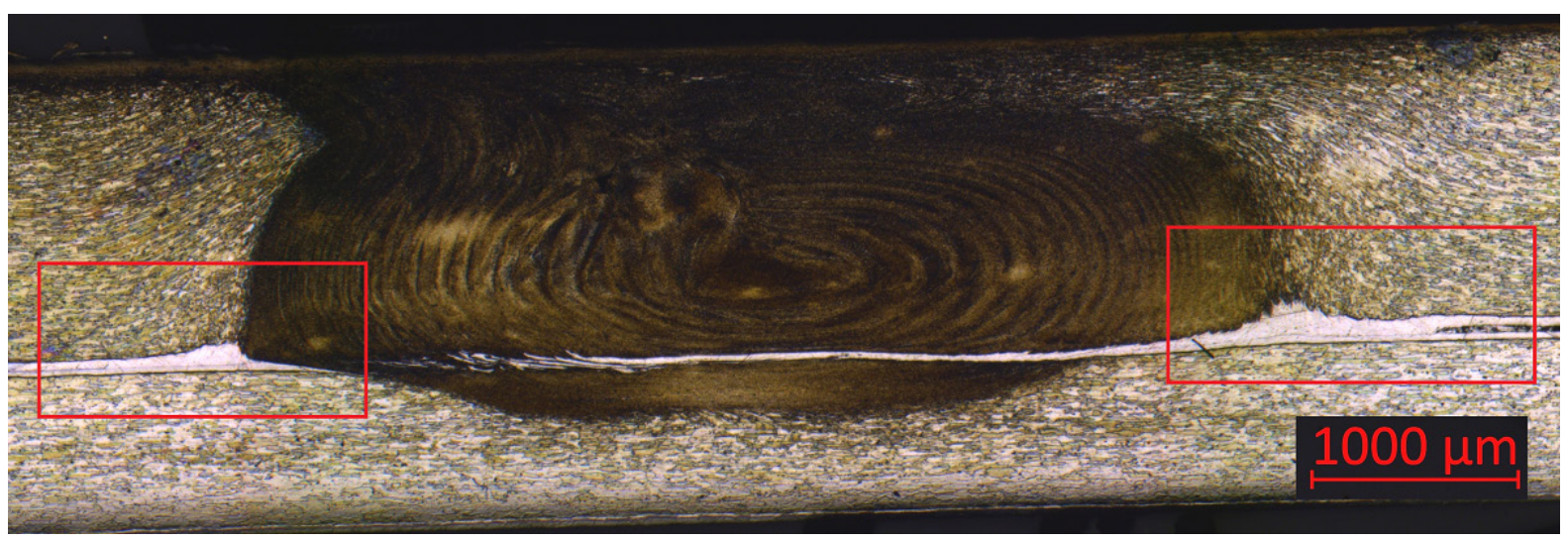

Fig. 4. Microstructure of joint welded with parameters: $\omega=1300 \mathrm{rpm} ; \mathrm{v}=100 \mathrm{~mm} / \mathrm{min} ; \mathrm{x}=0,3 \mathrm{~mm}$

During welding using a tool with an eccentricity value of $\mathrm{x}=0.3 \mathrm{~mm}$, machine vibration was observed, while less eccentric tools were used, the machine was more stable. This confirms the assumption that during using eccentric tools, the plasticity of the material in the weld is lower, and therefore, it results in higher resistance to the tool and consequently to the $\mathrm{CNC}$ machine.

The results of the strength tests are given in Table 3 and Figure 5. At lower rotational speeds, the load capacity of the joint decreases $(1 \div 1.5$ $\mathrm{kN})$ with increasing tool eccentricity. The consequence of the eccentricity of the tool combined with low rotational speed is the appearance of voids in the weld nugget (Table 3). The higher feed rate (linear speed) is, the bigger the voids are. This fact is a result of too low temperature in a weld and not sufficient plasticization of the material [4]. Higher rotational speed $(\omega=1300$ rpm) limits formation of voids, but when the feed rate is not sufficient and eccentricity is lower than $0.2 \mathrm{~mm}$ hooking is formed on the advancing side. The presence of hooking leads to worsening of mechanical properties of a joint (Fig. 5).
The samples subjected to a static tensile test, which carried a force of min. $6 \mathrm{kN}$ were broken in the weld on the advancing side. Joints of capacity lower than $6 \mathrm{kN}$, mainly joints welded with rotational speed of $700 \mathrm{rpm}$ with tools, which eccentricity was $0.2 \mathrm{~mm}$ or more, broke because of delamination of a weld. Large voids were found. They were oriented along the contact line of sheets.

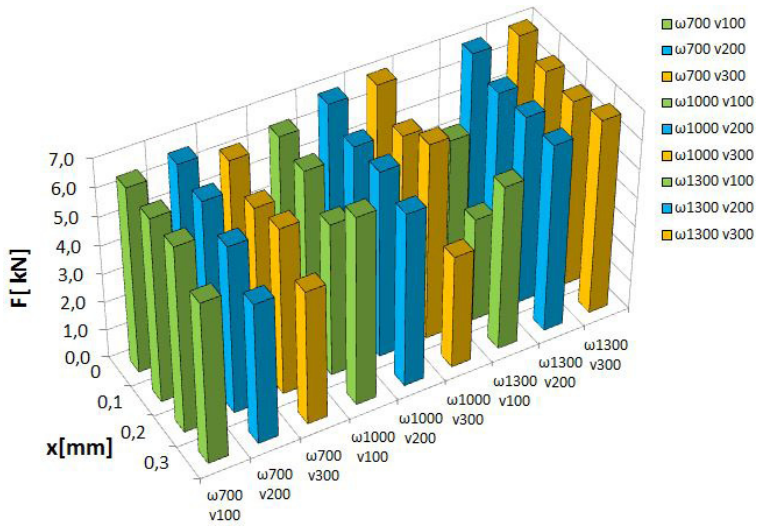

Fig. 5. Impact of FSW process parameters on tensile strength of joints ( $\omega[\mathrm{rpm}] ; \mathrm{v}[\mathrm{mm} / \mathrm{min}])$

Table 3. Tensile tests results

\begin{tabular}{|c|c|c|c|c|c|c|c|c|c|}
\hline$v$ & $\omega$ & $F_{x=0}$ & $S D$ & $F_{x=0.1}$ & $S D$ & $F_{x=0.2}$ & $S D$ & $F_{x=0.3}$ & $S D$ \\
\hline$[\mathrm{mm} / \mathrm{min}$ & {$[\mathrm{rpm}]$} & \multicolumn{7}{|c|}{$[\mathrm{kN}]$} \\
\hline 100 & 700 & 6.492 & 0.040 & 6.439 & 0.122 & 6.493 & 0.020 & 5.642 & 0.177 \\
\hline 200 & 700 & 6.672 & 0.170 & 6.391 & 0.141 & 5.857 & 0.374 & 4.927 & 0.111 \\
\hline 300 & 700 & 6.199 & 0.166 & 5.549 & 0.028 & 5.826 & 0.284 & 4.695 & 0.239 \\
\hline 100 & 1000 & 6.412 & 0.251 & 6.188 & 0.045 & 5.333 & 1.220 & 6.572 & 0.197 \\
\hline 200 & 1000 & 6.922 & 0.017 & 6.410 & 0.025 & 6.508 & 0.460 & 6.054 & 0.207 \\
\hline 300 & 1000 & 7.011 & 0.067 & 6.183 & 0.116 & 6.823 & 0.109 & 3.946 & 0.811 \\
\hline 100 & 1300 & 3.946 & 0.811 & 5.434 & 1.228 & 3.631 & 0.612 & 5.738 & 1.051 \\
\hline 200 & 1300 & 6.938 & 0.042 & 6.479 & 0.107 & 6.570 & 0.464 & 6.542 & 0.050 \\
\hline 300 & 1300 & 7.058 & 0.036 & 6.649 & 0.071 & 6.526 & 0.341 & 6.793 & 0.142 \\
\hline
\end{tabular}

SD - standard deviation 
Comparing joints welded with tools made without eccentricity with welded with eccentric tool, it can be stated that the tool with eccentricity $\mathrm{x}=0.2 \mathrm{~mm}$ and $\mathrm{x}=0.3 \mathrm{~mm}$ reduces the strength of the couplings. It should be emphasized that all the results obtained from the strength tests are characterized by high repeatability, which is evidenced by the small values of standard deviation, although the FSW thin sheet welding process is particularly sensitive to variations in parameters.

\section{CONCLUSIONS}

Based on the conducted research, it can be stated that:

- the weld faces of the joints made with eccentric tools were worse in quality, compared to the weld faces of the joints made with the tool without eccentricity,

- the use of eccentricity in FSW tools has a significant effect on the microstructure of the joints: the greater the too eccentricity is, the more heterogeneous the structure can be obtained, and at low rotational speed there are voids due to insufficient plasticization of the material,

- the most homogeneous microstructure was obtained by using high rotational speed, eccentricity free tools and high feed rate processes. In the microstructure of the joints so called onion rings can be observed,

- eccentricity of a tool limits the deformation of the contact line (e.g. hooking) on both sides of welds- advancing and retreading,

- the highest strength was presented by joints made with an non-eccentric tool or with a tool with eccentricity value: $\mathrm{x}=0.1 \mathrm{~mm}$. In most of the analyzed cases (Table 3), the strength of these joints was over $90 \%$ of the load capacity of thinner sheet material. These joints were broken through a thinner sheet on advancing side of a weld.

\section{Acknowledgements}

Financial support of The National Centre for Research and Development, European Union, PZL Mielec A Sikorsky Company in the framework of European Regional Development Fund
Project "Advanced techniques for the fabrication of airframe structures using innovative friction stir welding (FSW) technology", Nr INNOLOT/I/4/ NCBR/2013 is gratefully acknowledged.

\section{BIBLIGRAPHY}

1. Buffa G., Campanile G., Fratini L., Prisco A.: Friction stir welding of lap joints: influence of process parameters on the metallurgical and mechanical properties, Materials Science and Engineering A 519 (2009), 19-26.

2. Elangovan K., Balasubramanian V., Babu S.: Predicting tensile strength of friction stir welded AA6061 aluminium alloy joints by a mathematical model, Vol.30, Issue 1 (2009), pp. 188-193.

3. Guo N., M.R. Wang, Meng Q., Zhou L., Tang D.Y.: Effect of tool eccentricity on surface periodic banded structures in friction stir welding, Materials Science and Engineering 103 (2015).

4. Khodaverdizadeh H., Heidarzadeh A., Saeid T.: Effect of tool pin profile on microstructure and mechanical properties of friction stir welded pure copper joints, Materials and Design 45 (2013), pp. 265-270.

5. Leonard A. J., Lockyer S. A.: Flaws in friction stir welds, in: Proc. of 4th International Friction Stir Welding Symp. Utah, USA, 14-16 May, 2003.

6. Shaaban Essa A. R., Zaky Ahmed M., Ahmed Mohamed A.K., El-Nikhaily A. E.: An analytical model of heat generation for eccentric cylindrical pin in friction stir welding, Journal of Materials Research and technology 5(3), (2016), pp. 234-240.

7. Thomas W.M., Nicholas E.D.: Friction stir welding for the transportation industries, Materials and Design 18 (1997), pp. 269-273.

8. Xiu W.F., Liu J.H., Zhu H.Q., Fu L.: Influence of welding parameters and tool pin profile on microstructure and mechanical properties along the thickness in a friction stir welded aluminum alloy, Materials and Design 47 (2013), pp. 599-606.

9. Yuquing M., Liming K., Frencheng L., Qiang L., Chunping H., Li X.: Effect of tool pin eccentricity on microstructure and mechanical properties in friction stir welded 7075 aluminum alloy thick plate, Materials and Design 62 (2014), pp. 334-343.

10. Zhang Y.N., Cao X., Larose S., Wanjara P.: Review of tools for friction stir welding and processing, Canadian Metallurgical Quarterly vol. 51 (2012), pp. 250-261. 